\title{
Juan Carlos Moreno Romo, 2013. HambRe DE DIOS. ENTRE LA FILOSOFÍA, EL CRISTIANISMO Y NUESTRA DIFICIL Y FRÁGIL LAICIDAD MÉxico:Editorial Fontamara, 170 PP.
}

Desde un existencialismo cartesiano, Juan Carlos Moreno deja ir un señuelo muy bien preparado, meditado y sazonado para quien tiene hambre de Dios. Digo que es desde un existencialismo cartesiano porque, ya desde el primer ensayo del libro -y el ensayo es probablemente una de las formas más genuinas de hacer filosofía-, Moreno Romo se sitúa en el corazón de la filosofía de Descartes, delineando para su lector una alternativa frente a la existencia: la esperanza absoluta, o el abandono a la nada.

Para evitar aún más toda confusión: si le llamo "existencialista cartesiano" y no "cartesiano existencialista" es porque él piensa antes la existencia que a Descartes, aún cuando lo haga principalmente desde lo que Descartes mismo pensó sobre ella. Ejemplar exótico dentro de la academia, Moreno Romo es un filósofo real, es decir, piensa la vida y no solamente piensa a Descartes. Y eso es lo que importa.

El tema principal de su pensamiento en este libro es la necesidad que de Dios tiene el ser humano, y no es gratuito que haya llamado "hambre" a esta necesidad: la sitúa en lo biológico, en ese lugar ontológico desde el que ha de situarse la posibilidad de la existencia misma, y no en el lugar de las bagatelas o las inútiles joyas de la corona. No se trata aquí de hacer lo que la mayoría de las universidades hacen: pensar lujosamente los derechos humanos, o pensar lujosamente a Aristóteles, a Hegel o a Frege. Juan Carlos Moreno intenta decirnos que Dios es una imperiosa necesidad sin cuya satisfacción (al menos escatológicamente hablando) la vida humana sería nada menos que imposible. Otra cosa es decir que sustentar esta idea sea una empresa fácil.

Optar por un existencialismo cartesiano tiene la ventaja para el profesor Moreno Romo de permitirle pensar la existencia desde una 
encrucijada y no desde una posición comodina, pues Descartes se sitúa en el origen mismo de la Modernidad y pensar a Dios desde ahí no es nada fácil. En este libro no se habla de Dios desde un lugar que nada tiene que decirle al hombre del siglo XXI, sino que comienza ya-como Péguy en su momento o, en cuenta regresiva, Pascal o San Agustín o San Pablo- desde la premisa de que el mundo está descristianizado y de que cuando hay que hablar de Dios, hay que hacerlo sobre todo a hombres no cristianos.

No obstante, aunque Juan Carlos Moreno acepta, porque es un hombre de sentido común, esta premisa moderna como una situación de facto, no acepta muchas otras de la Modernidad como situaciones de iure, pues instala su existencialismo, si bien dentro del espíritu moderno en un sentido, también en otro sentido lo hace en contra de él.Y en muchos sentidos podría decirse que Hambre de Dios es un libro en el que arremete en favor y en contra de la Modernidad, aunque quizá más en contra que a favor.

De la Modernidad, dice: "Occidente tuvo que elegir y optó por la libertad y por el nuevo impulso espiritual que se le ofrecían en la nueva ciencia y la nueva filosofía. [...] [La filosofía de la Modernidad está] carente de diálogo, agreguemos, y carente de proyecto y de responsabilidad y carente de seriedad” (p.25). ${ }^{1}$ Pero esta calificación de la Modernidad no es exclusiva de ella, sino también de lo que luego ha venido a llamarse según algunos, "posmodernidad": "a la cultura occidental, como apuntan, como gritan, como predican escandalosamente los nihilistas que se hacen llamar "posmodernos", se le ha muerto Dios, se la muerto el Hombre y se le ha muerto el Ser. La cultura occidental ha perdido la philos-sophia y se ha perdido a sí misma.” (p.25).

Para recuperar a estos hombres exploradores de la Modernidad que se han perdido a sí mismos y que han perdido al mundo a cambio de las coordenadas matemáticas del mundo, propone en primera instancia el profesor Moreno Romo una apuesta por la cultura y por el estudio y por el amor a todas las perfecciones a las que el hombre puede estar llamado (las ciencias, las humanidades, las

1 El subrayado es del autor. 
artes, las habilidades retóricas), y esto dicho no solamente al globo entero sino también, y quizá más que nada ni nadie, al interior de la Iglesia pues, humildemente, ya desde el segundo ensayo, Juan Carlos Moreno reconoce que esta Iglesia Católica lleva una parte de la responsabilidad de la crisis contemporánea de mística y crisis de todo, en la medida en que los sacerdotes y los laicos miembros de ella suelen ser los últimos o los penúltimos o, en el mejor de los casos, antepenúltimos, en la apuesta por la cultura, el saber y la ciencia. Juan Carlos Moreno invita así al creyente a pensar por sí mismo, a ilustrarse. Aunque, como veremos más adelante, al no creyente lo invita a muchas otras cosas, entre ellas, a ilustrarse también.

Este atrevimiento del profesor Moreno Romo se reitera en el ensayo tercero, del que el libro toma nombre. Si bien podría parecer que en el mundo contemporáneo hay una vuelta a la religiosidad sobre todo a partir de algunas formas orientales, advierte que tan peligroso como un mundo en el que Dios ha muerto, es un mundo en el que se tome a los ídolos y vellocinos por el Dios verdadero. Hay que emprender, pues, nuevamente, y aquí se muestra una vez más este existencialismo cartesiano que tiene fe en la razón, un camino filosófico que se atreva a perderse en "la noche del mundo" expresión que el autor toma de su profesor Alfredo Troncoso, pero abiertos a que la salvación y la aurora pueden ser posibles una vez pasada la noche.

Hoy más que nunca es necesaria una vuelta a la fe en la razón, a pesar de que a ésta se le haya tomado por la sinrazón, madre de innumerables desgracias, de modo que los hombres debemos atrevernos a cuestionar nuestra propia vida hasta el fondo sin dejar de hacer absolutamente ninguna de las preguntas que la existencia nos plantee. Y "si la filosofía debe ser cuidadosa y desconfiada como la prudente y fiel soberana de Ítaca - señala Juan Carlos Moreno- también debe, como ella, estar abierta a la llegada del esposo" (p.38), es decir, a la llegada de algo más grande que ella y que reconcilie su constante inquietud con alguna respuesta más sosegada. Somos hambre de Dios y esa hambre es, primordialmente, como toda hambre, un dolor que punza en el estómago y nos recuerda nuestra inminente mortalidad, pero es ese punzón el que nos coloca en situación de abrirnos, ¿por qué no?, a que esa hambre pueda ser saciada. 
En "El Dios de los filósofos", que es el cuarto artículo de este trabajo, Juan Carlos nos deja por escrito una interesantísima conferencia que tuvo lugar en el Seminario Conciliar de la Diócesis de Querétaro el 17 de febrero de 2009 y, lo que es aún mejor, deja constancia de las participaciones de los asistentes, como en actas de un diálogo real: pregunta, respuesta, pregunta, respuesta, que permite de alguna manera volver a vivir el acontecimiento filosófico en el que, rodeado de seminaristas, se atrevió el profesor Moreno Romo a pensar en ese "Dios de los filósofos" de la tradición helénica más pura. De la mano de fragmentos de Homero, Heráclito, Jenófanes y Parménides, habla del Dios de los filósofos como uno que puede concebirse en consonancia con el Dios que aparecía, en paralelo, en el Sinaí y luego en voz de los profetas del pueblo Israel. Con esto el profesor Moreno Romo comienza a destrabar una tensión que, con la Modernidad, y quizás en especial por alguna ambigüedad de Pascal, puso en entredicho las nupcias entre el pensamiento religioso y la filosofía secular.

Con todo, el existencialismo cartesiano de Juan Carlos Moreno aún aquí se mantiene fiel a su leitmotiv, pues apuesta por esta armonía entre ambas consideraciones de Dios - la de la razón y la de la fe- e incluso aplaude la existencia de un cierto ateísmo en los filósofos modernos que, así, "se distancian, a su manera, de la idolatría, y cumplen de ese modo -imperfectamente si se quiere, negativamente tan solo- el primer mandamiento de la ley de Dios" (p.65). Sin embargo, completa este festejo con la prudentísima y valiosísima para el quehacer filosófico advertencia de siempre comenzar desde la humildad: no pensando que se sabe, sino adquiriendo conciencia de que en realidad no se sabe casi nada, y de que siempre se ha de estar en guardia tanto de afirmar que de Dios no se conoce nada como de que uno es el portador del verdadero mensaje que Dios tiene para los hombres. El diálogo con los seminaristas y profesores de seminario que es rescatado en este artículo es, por eso, riquísimo y fecundísimo.

Las reflexiones sobre las posibilidades de hablar de Dios en la universidad actual, inserta ella en un mundo secularizado, continúan en los siguientes trabajos del libro. En su artículo "Entre el Dios 
de la fe y el Dios de los filósofos”, que publicó en esta misma revista por primera vez, se ocupa precisamente de ese tema desde el punto de vista de la verdad y la relación que guarda la filosofía con ella. Sin verdad, sencillamente no hay filosofía ni saber de ningún tipo, y la cuestión de Dios debe ser explícitamente tratada en el seno de las investigaciones más honestas sobre la verdad y la posibilidad de conocer el mundo. Además, se hace en este artículo un tránsito de lo que sucede en la universidad y al interior de la filosofía misma a lo que sucede en el mundo político y en la esfera pública, pensando lo que le sucedió al papa emérito Benedicto XVI cuando en la universidad de La Sapienza le prohibieron la entrada y el micrófono simplemente por tratarse del papa.

En el penúltimo ensayo, "Nuestras coordenadas religiosas", Juan Carlos Moreno desenmascara esa frágil voluntad, transformada en aún más frágil deseo, incapaz en el siglo XXI de sacrificarse por nada como no sea sí misma en un instante determinado del tiempo. Toda meta vital que implique un poco el don de sí para algo que no sea sí mismo es temido como el peor de los infiernos sobre la Tierra.Y así, desenmascarando varias paradojas del mundo secular, moderno, globalizado, capitalista y demás mottos calificativos, emprende una agudísima crítica que recuerda el estilo chestertoniano de la paradoja. Se hace, Juan Carlos Moreno, crítico de un mundo que, queriendo ser laico, sacraliza al Estado; que queriendo ser libertario, moraliza la vida privada de sus políticos; que, queriendo ser plural, no admite posturas religiosas; que, queriendo concebir un Estado neutro en lo moral, no cesa de educar a sus jóvenes y de decirles qué deben concebir como bien y como mal; que, queriendo defender a las mujeres, no hace sino decirles qué hacer e imponerles deberes insportables. Veamos un ejemplo:

Si la Iglesia católica mantiene sus confesionarios en el silencio y en la intimidad, y en la difícil sinceridad de un exigente examen de conciencia en el que el penitente se abre, con la ayuda del sacerdote, a Dios y a su misericordia, y si esto ocurre, sobre todo, en el estricto secreto de confesión, la novísima y flamantísima Iglesia global abre los suyos, en cambio, y con todo el ruido del 
que es capaz, a los cuatro vientos. Así, no es uno solo el que, reconciliado con Dios y consigo mismo, se lleva un "vete en paz", sino que son muchos los que se entretienen, y se ensañan, en una muy excitante lucha de implacables jueces y verdugos contra el incuestionable mal.

Pero la del reality show es una confesión Light y catártica que, si trata de pecados feos, no trata, desde luego, de todos los pecados. Un presidente de los Estados Unidos puede, por ejemplo, ordenar que se arrojen un par de bombas atómicas sobre otro par de muy pobladas ciudades japonesas [...] o puede incluso empujar al harto despreciado país vecino a una estúpida "guerra contra el narcotráfico" mientras facilita, o por lo menos se hace de la vista gorda en lo que se refiere a un contrabando de armas [...] Pero lo que no se le perdona a un presidente de los Estados Unidos, es que en sus horas de trabajo engañe a su mujer con una de sus becarias (p.154).

Sí. Tenemos hambre de Dios, pues ya no sabemos qué es el bien y qué es el mal. Es verdad que lo hemos confundido todo. Y, si no todo, muchas cosas. El libro del profesor Moreno Romo no hace sino recordarnos de esa hambre que, enviada al cuarto de los trastos viejos, actúa sólo como una molestia a la que no sabemos darle nombre y resolvemos con agresividades de varios tipos o con terapias psicoanalíticas tan largas como la cartera y la paciencia nos lo permiten. Por eso su último trabajo, "En el corazón del escándalo" pone los puntos sobre los íes acerca de algunos de los escándalos mediáticos que el emérito papa Benedicto XVI ocasionó y que muchos señalaron que se debía a lo que llamaban "imprudencia diplomática" y otros, quizás más sensatos, reconocieron simplemente como valor para decir la verdad.

Las fuentes principales de Juan Carlos Moreno las encontramos en Descartes, Unamuno, Husserl y San Agustín. Es un libro moderno pero también antiguo y, quizás por ello, perenne. Lo que me ha parecido más loable de todo él es, respecto del hambre de Dios, la recuperación que se hace de la razón, tan necesaria y nunca sobrante, en el itinerario existencial de una persona que se pregunta por 
la verdad. Si bien esto me parece una verdad tan importante como innegable, hay quizás una pequeña omisión $-\mathrm{o}$ consideración unilateral- en todo el libro, y que estoy seguro que el mismo Juan Carlos Moreno podría decir algo al respecto. Me refiero a que la razón es concebida, o mostrada, como eminente y unilateralmente individual y teórica, y no se pone atención a la necesidad de la intersubjetividad para que esta razón se constituya como tal: no se pone el suficiente énfasis, a mi juicio, en el imprescindible papel que el prójimo tiene en mi propio encuentro con la verdad, por lo que parece considerar a la razón y a la filosofía como algo exclusivamente teórico.

Está claro que el profesor Moreno Romo no excluye la acción ni los avatares de la existencia en la labor filosófica, pero no parece tampoco afirmar -sobre todo respecto del modo como podría saciarse esa hambre de Dios que ha puesto sobre la mesa- que es la vida misma, de la mano de la reflexión teórica -y no la reflexión teórica de la mano de la vida misma como quizás pareciera él decirla que muestra al hombre quién es y cómo es frente a Dios.

No digo esto solamente porque pudiera tener yo un mayor gusto por la francachela que por las difíciles horas de biblioteca, sino porque el drama existencial sobre Dios no puede resolverse en la teoría, aunque requiera de ella para llegar a su resolución. No es gratuita la dialéctica casi desesperante del incipt de las Confesiones de San Agustín: “dame, Señor, a conocer y entender qué es primero, si invocarte o alabarte, o si es antes conocerte que invocarte. Pero ¿quién podrá invocarte si antes no te conoce? Porque, sin conocerte, fácilmente podrá invocar una cosa por otra. ¿Acaso, más bien, no habrás de ser antes invocado para ser conocido? Pero, ¿cómo invocarán a aquél en quien no han creído? ¿Y cómo creerán si no se les predica?” (Agustín de Hipona, Confesiones: I, 1, 1). Si bien el problema que más explícito se presenta en esta paradoja es el de la relación entre la fe y la razón, en la última afirmación que a modo de pregunta hace Agustín queda claro que el dilema solamente puede resolverse en la práctica, con la llegada de una alteridad que me predique $-\mathrm{y}$ la única predicación digna de tal nombre es el amor-que puede haber un Dios que me salve del atolladero de mi radical soledad. 
Es en la acción en donde aprendo las verdaderas lecciones de la vida, aunque este hacer y este actuar tengan que ir acompañados de un estrictísimo examen de las proposiciones sobre las que este mismo actuar se sustenta. Y, ya por dejar ir la pluma más lejos aún, podría decirse que es en la acción que sobre mí ejerce gratuitamente otro - es decir, en su predicación, y por predicación no puede entenderse otra cosa que el ejercicio de la palabra dicha y encarnada, como Mónica y Ambrosio en el caso agustiniano--, y no tanto en la acción que está en mis propias manos, en donde aprendo las verdades más radicales de la vida, por lo que la meditación solitaria es un bien siempre necesario pero también siempre insuficiente para que aquello que sea Dios pueda advenir no solamente a la idea, retomando expresión de Lévinas, sino al corazón mismo de mi vida. No basta, pues -aunque sea un necesario imperativo-, mi propio ejercicio racional, ni mi sola actividad heroica, sino que ha de acontecer algo gratuito para que yo pueda aprender a Dios.

Si bien esto no está explícitamente dicho por el profesor Moreno Romo, y quizás habría que decir que tal vez sea porque con esta afirmación entramos prácticamente en terreno teológico, no cabe duda de que Hambre de Dios es un libro imprescindible y necesario, pues a pesar de atacar problemas filosóficos de primer orden, no pretende solucionar los grandes misterios porque sabe humildemente que éstos no han de ser solucionados; pero sí abre las puertas a que la razón se deje interpelar por ellos y, en específico, por el misterio más grande, el de la totalidad del bien y de la verdad que, si bien es un misterio que puede tener que ver más con la teología, también es verdad que Dios es el misterio más filosófico de todos.

Diego I. Rosales Meana

Centro de Investigación Social Avanzada

diego.rosales@cisav.org 